\title{
LIMPAPEH PADA BAJU KURUANG BASIBA
}

\author{
Rahmawati $^{1^{*}}$, Ahmad Akmal $^{2^{*}}$, Awerman $^{3^{*}}$ \\ Minat Penciptaa Seni Kriya Program Pascasarjana \\ Institut Seni Indonesia Padang Panjang \\ Jl. Bahder Johan, Guguak Malintang, Padangpanjang, Kota Padangpanjang, 27126. \\ Sumatera Barat. Indonesia. \\ Email: wati250592@gmail.com
}

\begin{abstract}
Abstrak
Limpapeh atau attacus atlas merupakan kupu-kupu besar dengan bentangan sayap yang luas, yang memiliki warna coklat kemerahan dan dihiasi sedikit warna putih. Kebiasaan limpapeh hinggap pada rumah, bangunan, pepohonan, dedaunan dan bunga yang sedang bermekaran. Bagi masyarakat Minangkabau limpapeh adalah sebutan untuk perempuan Minangkabau yang sudah beranjak dewasa yang bertanggung jawab menjaga garis keturunan berikutnya, berdasarkan garis keturunan ibu yang akan menjadi penghuni dalam rumah gadang. Bentuk limpapeh dalam penciptaan karya ini adalah sebagai motif dari baju kuruang basiba, baju kuruang basiba merupakan pakaian perempuan Minangkabau yang mempunyai ciri khas yaitu pada bagian samping baju terdapatnya siba dan kikik. Bentuk sayap limpapeh yang terdapat pada bagian dada, lengan dan bawahan baju serta bentuk limpapeh yang berbentuk utuh yang berterbangan sehingga membuat baju kuruang basiba, ini lebih menarik.
\end{abstract}

Kata Kunci: limpapeh, baju kuruang, basiba

\begin{abstract}
Limpapeh or attacus atlas is a large butterfly with a broad stretch of wings, which has a reddish brown color and is decorated with a little white color. The habit of leaking on the house, building, trees, leaves and flowers are blooming. For Minangkabau people limpapeh is a term for Minangkabau women who have grown up who are responsible for maintaining the next lineage, based on the maternal lineage that will become residents in the gadang house. The form of limpapeh in the creation of this work is as a motif of kuruang basiba clothes, kuruang basiba clothes are Minangkabau women's clothing which has the characteristic that on the side of the shirt there is siba and kikik. The limpapeh wing shape that is found on the chest, arms and subordinates of the clothes as well as the full shape of the limpapeh which flies to make kuruang basiba clothes, this is more interesting.
\end{abstract}

Keywords: limpapeh, kuruang basiba's clothes

\section{PENDAHULUAN}

Limpapeh adalah kupu-kupu besar atau kupu-kupu gajah, dengan nama latin attacus atlas. Nama attacus atlas ini diberikan karena bentuk sayap kupu-kupu yang besar dan sayapnya yang berbentuk atlas (Shadily, 1983: 1919). Kupu-kupu gajah memiliki warna cokelat kemerahan dan dihiasi sedikit warna putih. Orang Minangkabau menyebut kupu-kupu tersebut dengan sebutan limpapeh, kupu-kupu gajah mempunyai sifat yang baik yaitu terbang yang tidak tinggi, suka hinggap pada tempat-tempat seperti, rumah, bangunan-bangunan yang besar, pepohonan, dedaunan, dan pada tumbuhan bunga yang sedang bermekaran. Limpapeh di Minangkabau merupakan sebutan untuk kaum perempuan atau anak gadis yang mendiami rumah gadang (Marah, 1987: 26).

Perempuan yang disebut limpapeh adalah perempuan yang telah beranjak dewasa, yang telah berumur lima belas tahun atau lebih, masa ini adalah masa untuk mempersiapkan diri menjadi limpapeh rumah nan gadang (Boestami, 1992: 102). Masa dari persiapan ini adalah masa bagi perempuan Minangkabau yang akan meninggalkan masa kanak-kanak dan akan 


\section{Gorga Jurnal Seni Rupa \\ Volume 07 Nomor 02 \\ p-ISSN: 2301-5942 | e-ISSN: 2580-2380}

beranjak dewasa. Limpapeh rumah nangadang merupakan perumpamaan bagi seorang perempuan di Minangkabau yang bertanggung jawab menjaga garis keturunannya dan generasi penerusnya berdasarkan garis keturunan ibu. Pengambaran hidup tersebut juga tercermin dalam berpakaian perempuan Minangkabau, yaitu berpakaian yang menutupi aurat. Pakaian yang dipakai oleh perempuan Minangkabau yang dikenal dengan baju kuruang basiba.Baju kuruang basiba adalah baju longgar yang panjang sampai lutut yang menutupi seluruh anggota badan, dengan lengan panjang sampai pergelangan tangan yang lapang atau longgar (Ibrahim,1986: 114). Baju kuruang basiba mempunyai ciri-ciri yang khusus seperti siba, siba tersebut ditandai oleh tiga tanda jahitan yang berawal dari ujung ketiak sampai bawahan baju.

Berdasarkan uraian di atas pengkarya mengangkat limpapeh sebagai motif pada baju kuruang basiba, karena diantara keduanya memiliki saling keterkaitan. Baju kuruang basiba ini diciptakan bertujuan untuk acara pesta perempuan dewasa dengan adanya bentuk modifikasi pada lengan baju yang berbentuk sayap limpapeh dan adanya bentuk lengan panjang pada bagian bawah. Dalam penciptaan karya pengkarya menggunakan teknik batik tulis dan sulam hias yang terdapat pada bentuk limpapeh dan pada sayap limpapeh.

\section{KAJIAN TEORI}

\section{Batik}

Batik adalah gambar atau hiasan yang berawal dari kumpulan titik- titik pada kain yang proses pengerjaannya dilakukan dengan penutupan dengan bahan lilin atau malam dan kemudian diberi warna (Musman, 2011: 1). Teknik batik yang akan digunakan adalah teknik batik tulis diterapkan pada bentuk sayap limpapeh, bagian yang dibatik diantaranya bentuk sayap limpapeh yang terdapat pada bagian lengan, pada bagian dada, pada bagian bawah baju dan pada bagian rok.

\section{Sulaman}

Sulaman adalah hiasan yang dibuat di atas kain atau bahan-bahan lain dengan jarum jahit dan benang. Sulaman merupakan keterampilan yang dapat dilakukan dengan bahan seperti benang dengan media dan alat yang sesuai ( Suhersono, 2001: 12 ). Sulam benang yang terdapat pada bentuk sayap limpapeh yang terdapat pada bagian lengan, pada bagian dada, pada bagian bawah baju dan bagian rok sebagai pengisi bidang serta penganti isen-isen dari batik tulis yang terdapat dalam bentuk sayap limpapeh. teknik sulam yang digunakan adalah sulam batang dan sulam tusuk peniti, dan sulam payet.

\section{Bentuk}

Limpapeh sebagai ide penciptaan karya seni disebut juga dengan kupu-kupu gajah karena bentuk dari sayapnya yang berbentuk atlas. Menurut Ensiklopedi Indonesia kupu-kupu gajah adalah kupu-kupu yang bersayap luas, berbadan tebal, bentangan sayap sampai $25 \mathrm{~cm}$ dan panjang $15 \mathrm{~cm}$ bewarna coklat kemerahan dan di hias sedikit warna putih, sayap yang mempunyai bercak berbentuk mata (Shadily, 1983: 1919).

Limpapeh yang terlihat pada gambar di atas berdasarkan studi lapangan yang hinggap pada batang pohon, hal tersebut merupakan bahwa limpapeh selalu hinggap di tempat seperti di rumah, bangunanbangunan yang besar, pepohonan, dedaunan, dan pada tumbuhan bunga yang sedang bermekaran.

limpapeh yang cantik dengan bentangan sayap yang luas oleh para seniman Minangkabau dijadikan sebagai orientasi dari motif limpapeh atau motif ukiran ragam hias Minangkabau. Bentuk limpapeh yang besar dengan bentangan sayap yang indah dijadikan limpapeh sebagai kiasan untuk perempuan yang mendiami rumah gadang (Zulhelman, 2001: 113).

Limpapeh sebagai simbol bagi seorang perempuan di rumah gadang, yang fungsi dalam menumbuh suburkan kehidupan, berbudi pekerti luhur dalam masyarakat. Budi luhur tersebut merupakan salah satu sendi dari pergaulan hidup yang bahagia, aman, dan tentram lahir batin. Sehingga kaum perempuan di Minangkabau merupakan penghuni rumah gadang yang memiliki sifat keindahan, mempunyai rasa malu, sopan santun, dan ramah.

\section{Baju Kuruang Basiba}

Baju kuruang basiba adalah baju yang longgar atau lapang yang menutupi aurat sampai ke batas lutut dengan lengan panjang sampai pergelangan tangan, dan leher tampa kerah. Hal ini dipertegas oleh Zulhelman bahwa baju kuruang basiba adalah baju yang longar dan lapang mempunyai kikik dan sibaberasal dari tiga tanda jahitan yang ada di bidang kain mulai dari ujung ketiak sampai kebawah pada kedua sisi baju (Zulhelman, wawancara: tanggal 11 Februari, 2016, Padangpanjang). Lebih lanjut Ibrahim menjelaskan bahwa baju longgar melambang bahwa pemakainya adalah perempuan yang melaksanakan ajaran agama Islam (Ibrahim,1986: 114). Selanjutnya 


\author{
Gorga Jurnal Seni Rupa \\ Volume 07 Nomor 02 \\ p-ISSN: 2301-5942 | e-ISSN: 2580-2380
}

Misnah menjelaskan bahwa baju kuruang basiba adalah baju kuruang karena si pemakai seakan-akan terkurung, hal ini disebabkan apabila si pemakai ingin membuka baju hanya dapat dibuka melalui kepala saja, tidak adanya belahan atau adanya resleting pada baju hanya ada belahan baju di atas dada pada bagian depan sekedar untuk meloloskan kepala saat di pakai atau di buka(Misnah, 2013: 19).

Siti Sanida Putri menambahkan baju kuruang basiba adalah pakaian yang longgar, tidak membentuk lekuk tubuh, dengan panjang baju sampai lutut dan adanya kikik dan siba. Kikik pada baju kuruang basiba mejelaskan atau melambangkan perempuan di Minangkabau harus mempunyai sifat-sifat yaitu: adanya sifat raso jo pareso, adanya sifat malu, dan adanya sifat sopan santun, yaitu tiga sifat yang harus di jaga dan di junjung tinggi oleh perempuan Minangkabau, seperti dalam pergaulan sesama besar antara laki-laki maupun perempuan, baik dalam keluarga atau famili maupun orang lain. Sedangkan siba adalah ulasan, sambungan menjelaskan bahwa perempuan di Minangkabau adalah perempuan yang taat pada agama yang memakai baju yang longgar tidak membentuk lekuk tubuh, yang menutup aurat serta tidak tembus pandang ( Siti Sanida Putri, wawancara: tanggal 4 Februari 2016, solok).

Asnimar juga menjelaskan bahwa baju kuruang basiba adalah pakaian yang menutup aurat berdasarkan syariat islam yaitu baju yang tidak membentuk dari bentuk tubuh, lapang dan longgar, adanya siba sebagai sambungan pada bagian samping serta kikik pada bagian ketiak, dengan panjang baju sampai lutut atau sedikit melebihi di bawah lutut, dan lengan panjang, leher tanpa krah dengan potongan atau guntingan krah dinamai dengan gunting tampuak siriah, di sebut sebagai guntiang tampuak siriah karena bentuk krah dari baju kuruang basiba dengan adanya sedikit belahan sebatas dada pada bagian depan yang menyerupai tampuaksiriah ( Asnimar, wawancara: tanggal 3 Februari 2016, Padangpanjang).

Pada saat sekarang ini pakaian sudah mengalami berbagai perubahan baik bentuk maupun jenisnya, pergeseran budaya yang telah terjadi di Minangkabau akibat dari adanya pengaruh yang datang dari luar dengan desain yang menarik. Perempuan lebih memilih pakaian dengan desain yang baru, lebih modis dan menggunakan warna yang menarik, serta pakaian tersebut telah mengikuti tren dalam berpakaian dan desain yang tidak ketingalan zaman, sebagaimana yang terlihat pada gambar hasil studi sebagai berikut ini.
Sebagai akibat dari perkembangan tersebut adat istiadat lama yang menjadi rambu-rambu perjalanan hidup masyarakat Minangkabau terkesan mulai diabaikan. Ketidakmampuan niniak mamak dan orang tua memerankan dengan sempurna fungsi-fungsi pendidikan di lingkungan terkecil, rumah tangga dan suku di Minangkabau sangat terasa, utamanya di dalam bidang pendidikan moral anak nagari yang mempunyai eksistensi dalam ajaran agama dan berbagai pendidikan lainnya. Penciptaan karya baju kuruang basiba ini adalah sebagai cambuk kembalinya tradisi lama ditengah-tengah kehidupan masyarakat Minangkabau sekarang.

\section{METODE PENELITIAN}

Untuk memperkuat ide dari penciptaan, digunakan beberapa landasan pemikiran agar karya yang dibuat mencapai bentuk dan wujud yang diharapkan. Dari sinilah sebuah karya akan terlihat menarik dan mempunyai nilai serta fungsi yang dapat dinikmati oleh orang banyak juga mendorong atau mendasari keinginan untuk menciptakan karya seni yang mengandung keindahan serta pesan-pesan moral melalui beberapa karya. Untuk memperkuat ide penciptaan karya seni ada beberapa landasan teori yang terkait, diantaranya:

Dalam tinjauan kriya ada beberapa hal yang dijelaskan baik dari bentuk karya maupun teknik yang digunakan. Bentuk dari karya yang berjudul limpapeh pada baju kuruang basiba ini menjelaskan bentuk limpapeh yang terdapat pada baju kuruang basiba serta penempatan pada bagian-bagian busana atau baju kuruang basiba, dan pengarapan karya ini pengkarya mengunakan teknik diantaranya: teknik batik tulis, sulam benang, dan sulam payet atau manik-manik. 

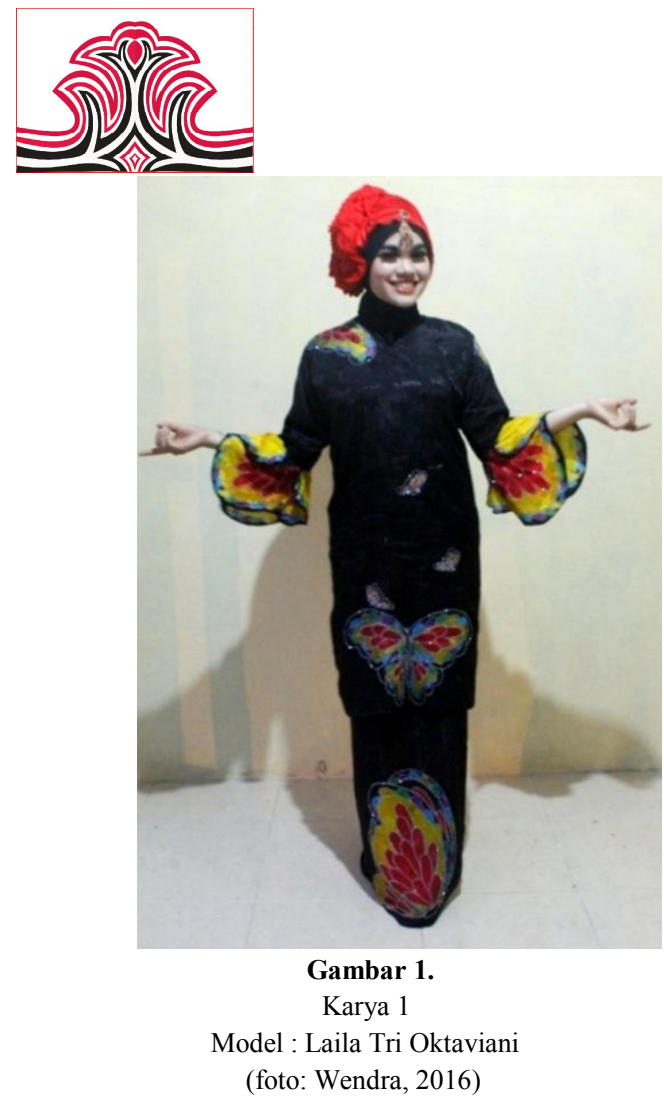

Karya yang secara visual dengan limpapeh besar yang terdapat pada bagian bawah baju dan pada bagian bahu, dan pada bagian lengan bawah serta pada bagian depan rok. Karya ini menjelaskan tentang kepemimpinan seorang perempuan Minangkabau untuk mendidik dan menjaga semua keturunannya, seorang perempuan di Minangkabau yang menjadi contoh bagi penerusnya dengan menggunakan pakaian yang menutup aurat berdasarkan syariat islam yang menutup seluruh anggota badan dan pakaian yang tidak membentuk lekuk tubuh. Pemenpatan limpapeh yang berukuran besar pada bagian bahu menjelaskan tentang perempuan di Minangkabau yang sudah dewasa akan mengemban tugas untuk menjaga nama baik diri dan nama baik seluruh keluarga.

Sedangkan limpapeh besar yang menghadap ke atas dengan bentangan sayap yang luas di tempatkan pada bagian bawah baju menjelaskan tentang perempuan di Minangkabau apabila telah beranjak dewasa akan mulai menatap masa depan, menjaga, melindungi, mendidik serta menyayangi yang lebih kecil, tergambar pada bentangan sayap yang luas pada limpapeh. Warna-warni yang terdapat pada sayap limpapeh juga menjelaskan tentang bagaimana kehidupan yang akan di jalani oleh perempuan apabila telah beranjak dewasa dan menghadapi semua tentang kehidupan ke depannya. Selanjutnya limpapeh besar yang penempatannya pada bagian depan rok dan limpapeh berukuran kecil yang terdapan di belakang menjelaskan limpapeh besar akan menjadi contoh tauladan bagi penerusnya dan menjadi yang terdepan untuk hal yang bersifat mendidik dan menjaga. Warna
Gorga Jurnal Seni Rupa

Volume 07 Nomor 02

p-ISSN: 2301-5942 | e-ISSN: 2580-2380

yang digunakan pada karya ini adalah warna hitam yang melambangkan kepemimpinan. Sedangkan untuk warna limpapeh yang tedapat pada baju kuruang basiba menggunakan warna merah yang melambangkan keberanian, kuning yang melambangkan keagungan, hijau yang melambangkan kesuburan, kesegaran, biru yang melambangkan ketenangan, ungu yang melambangkan kejayaan.

\section{PEMBAHASAN}

Sebuah karya seni selalu diawali dari sebuah desain atau rangcangan yang mana perancangan ini merupakan bahagian terpenting dalam membuat sebuah karya seni yang mempunyai nilai fungsi dan nilai estetika. Konsep penciptaan dari karya yang akan dibuat adalah konsep imitasi. Imitasi merupakan konsep yang meniru pada alam (Sugono, 2008: 528). Pada karya tugas akhir pengkarya meniru bentuk limpapeh sebagai ide pencitaaan karya, dengan alasan sayap limpapeh memiliki bentuk yang menarik, dengan sayap membentang luas dan hiasan yang unik pada bentangan sayapnya.

Pengambilan bentuk limpapeh dan bentuk sayap limpapeh di tempatkan pada beberapa bagian dari baju kuruang basiba seperti pada bagian dada, bagian lengan yang berbentuk limpapeh, bagian bawah baju seperti bentuk sayap limpapeh, dan pada bagian rok, serta adanya bentuk telur dari limpapeh dan bentuk akar sebagai bentuk pendukung karya dengan bentuk limpapeh. Model baju kuruang basiba pada karya ini berbentuk longgar yang panjang sampai lutut yang menutupi seluruh anggota badan, dan dengan bentuk lengan baju yang sudah di modifikasi, modifikasi menurut Kamus Besar Bahasa Indonesia adalah pengubahan, dilakukan untuk menbuat sesuatu lebih menarik dan tampil beda dari yang biasanya seperti pada karya yang berbentuk lengan yang panjang dan berbentuk sayap limpapeh.

Limpapeh dalam penciptaan karya ini, memiliki nilai keindahan, serta pesan yang disampaikan pada penikmat, serta adanya landasan teori bentuk dan teori fungsi yang mendukung terciptanya karya limpapeh pada baju kuruang basiba. Bentuk limpapeh pada bagian-bagian tertentu memiliki makna di setiap penempatannya. Rancangan karya limpapeh pada baju kuruang basiba ini sangat erat hubungannya karena kedua rancangan ini berhubungan dengan perempuan di Minangkabau.

Metode penciptaan ini merupakan suatu cara untuk mewujudkan karya seni secara sistematik. Tahap yang dilakukan diantaranya pengumpulan data seperti studi 


\section{Gorga Jurnal Seni Rupa \\ Volume 07 Nomor 02 \\ p-ISSN: 2301-5942 | e-ISSN: 2580-2380}

pustaka, melalui media internet yang sesuai dengan tema tersebut. Data-data yang dikumpulkan berupa tulisan atau teori maupun gambar sesuai dengan tema. Penciptaan karya seni ini mengacu pada paparan Gustami mejelaskan bahwa:

Dalam proses melahirkan karya seni khususnya seni kriya secara metodologis melalaui tiga tahap utama, yaitu (1) Eksplorasi, yang meliputi langkah penggambaran jiwa, dan penjelajahan dalam menggali sumber ide. (2) Perancanagan, yang terdiri dari kegiatan menuangkan ide dari hasil analisis yang telah dlakukan ke dalam bentuk dua dimensional atau desain. (3) Perwujudan, yang merupakan perwujudan menjadi karya (Gustami Sp, 2007: 329).

Sebelum menciptakan karya, terlebih dahulu melakukan survei dan pengamatan terhadap karyakarya yang telah ada, melakukan penggalian sumber referensi dari perpustakaan dan informasi dari media cetak maupun dari situs internet guna memecahkan persoalan dalam penciptaan karya. Kemudian menjiwai penggambaran tersebut guna melakukan pengembangan. Menyangkut segala sesuatu persepsi dan kemampuan untuk melakukan tindakan positif dipengaruhi secara langsung oleh pengamatan terhadap objek.

Pengamatan langsung pada objek di luar dan di lapangan merupakan hal acuan dalam pembuatan dan pencarian ide-ide yang nantinya dituangkan dalam berbagai desain dan perancangan bentuk baju kuruang yang akan dibuat. Perkembangan ilmu masyarakat lebih cenderung menyukai hal-hal yang baru dan unik untuk mempercantik diri dari sinilah dapat disimpulkan bahwa dengan adanya inovasi yang baru dalam rangcangan baju kuruang basiba akan membuat masyarakat tertarik.

Sebelum mewujudkan karya, terlebih dahulu melakukan penggalian ide yang berkaitan dengan bentuk yang akan divisualkan. Membuat gambarangambaran berupa desain. Mempertimbangkan segala sesuatu yang menyangkut bahan, alat, dan keteknikan untuk mewujudkan karya yang diciptakan.

Untuk rancangan karya ini pengkarya mengunakan kain santung bayi untuk bahan utama dengan ukuran 5 m panjang kain, dengan mengunakan warna remasol sebagai pewarna, warna yang digunakan adalah warna hijau untuk warna dasar kain, merah untuk warna limpapeh. Takaran untuk pewarna dasar adalah 1 ons warna biru ditambah atau dicampur dengan warna kuning 1 sendok makan. Sedangkan untuk warna limpapeh atau sayap limpapeh mengunakan takaran warna 10 gram warna merah dicampur dengan warna kuning sebanyak setengah sendok teh yang dicampur dengan menggunakan manutek untuk pengental agar warna tidak mudah cepat melebar dengan takaran manutek adalah 20 gram atau sesuai kekentalan yang di inginkan.

Dengan mengamati bentuk dari limpapeh, pencipta mencoba mengeksplorasi dalam beberapa bentuk seni kriya tekstil. Perwujudan tidak hanya sebagai media ekspresi, tetapi juga memberi nilai fungsi praktis di dalam penciptaanya.

\section{Bahan}

Kain santung bayi

Lilin atau malam

Benang sulam

Pewarna remasol

Payet atau manik-manik

Alat

Mesin jahit

Wajan dan kompor

Canting

Gunting

Kuas

Sendok dan mangkok

Panci

Kompor

Pita ukuran

Baskom

Ram

Teknik

Teknik sulam benang dan sulam payet.

\section{KESIMPULAN}

Limpapeh merupakan gambaran perempuan yang bersikap lemah lembut, penuh sopan santun, dan tutur kata yang penuh dengan tata krama. Limpapeh yang berorientasi pada kupu-kupu besar dengan nama latin attacus atlas yang di jadikan oleh seniman Minangkabau sebagai kiasan untuk perempuan Minangkabau, oleh karena itu perempuan yang sudah beranjak dewasa di Minangkabau akan menjadi limpapeh rumah nan gadang yang akan menghuni rumah gadang. Limpapeh juga berperan penting dalam hal pendidikan dan menjaga keturunannya, oleh karena itu orang Minangkabau mengikuti garis keturunan ibu. Limpapeh atau perempuan Minangkabau yang mencerminkan sikap dan budi pekerti yang baik tergambar pada cara berpakaiannya yaitu berpakaian yang menutup aurat, longgar, tidak ketat atau membentuk badan.
Jarum pentul

Teknik batik tulis 
Perancangan busana atau pakaian dengan tujuan agar dapat mengenalkan kembali ciri khas baju kuruang basiba pada masyarakat Minangkabau dengan bentuk modifikasi, dengan bentuk desain yang menarik serta dengan teknik-teknik yang berbeda yaitu dengan teknik batik dan sulam benang dan payet. Dengan adanya bentuk desain yang baru dan teknik-teknik yang berbeda diharapkan para perempuan Minangkabau bisa kembali tertarik menggunakan baju kuruang basiba.

\section{DAFTAR RUJUKAN}

Boestami, 1992, Kedudukan dan Peranan Wanita dalam Kebudayaan Suku Bangsa Minangkabau, Padang: C.U Trisufadli.

Esten, Mursal, 1993, Minangkabau Tradisi dan Perubahan, Padang: Angkasa Raya.

Feldman, Edmund Burke, 1967, Art As Image And Idea, Terjemahan SP. Gustami, 1991, Yogyakarta: FSRD ISI Yogyakarta.

Gustami, SP, 2007, Butir-Butir Mutiara Estetika Timur; Ide Dasar Penciptaan Seni Kriya Indonesia, Yogyakarta: Prasista.

Hakimy, Idrus, 1994, Pegangan Penghulu, Bundo Kanduang, dan Pidato Alua Pasambahan Adat di Minangkabau, Bandung: Remaja Rosdakarya

Ibrahim, Anwar, 1986, Pakaian Adat Tradisional Sumareta Barat, Jakarta: Departemen Pendidikan dan Kebudayaan.

Kartika, Dharsono, Soni, 2004, Seni Rupa Modren, Bandung: Rekayasa Sains. 